\title{
Surface Mesonets of the Western United States
}

\author{
Donna F. Tucker \\ University of Kansas, Lawrence, Kansas
}

\begin{abstract}
In recent years the western United States has gone from being a region with relatively sparse surface observations to one that has a number of mesoscale networks maintained by a variety of interests. Expanding population and increased agricultural activity have spawned a greater appreciation for meteorological measurements in this region. Yet the meteorological community is not generally aware of these data sources, and some potential research uses for the data are not realized. A survey of these mesonets is presented to illustrate the number of stations and the variations in their characteristics. Even though the networks have been set up by different agencies, there is very little overlap in their locations. Some areas in the region, however, are still lacking an abundance of surface data. Information sources for the networks are provided so that readers can obtain additional information. It can be difficult to work with data from several different sources. Nonetheless, it is recommended that the meteorological implications of these data be further explored. Additional efforts are also needed to establish standards for surface observations so that the data collected by various sources will be more uniform.
\end{abstract}

\section{Introduction}

In the past, the western United States has often been regarded as a meteorological data-sparse region when compared to the eastern United States. Although there have been a number of field programs (e.g., Knight 1982; Orgill and Schreck 1985; Cionco 1994), until several years ago surface data from fixed stations taken over a number of years were available at less spatial resolution than in the eastern United States. The relative lack of surface data was most likely due to the region's sparse population and rough terrain. Yet it is because of the dramatic spatial elevation changes that the western United States has greater horizontal variability in the values of meteorological surface variables than does most of the eastern United States.

Recent years have seen an expanding population in the western United States as well as a greater

Corresponding author address: Donna F. Tucker, Department of Physics and Astronomy, University of Kansas, Lawrence, KS 66045-2151.

E-mail: tucker@phoenix.phsx.ukans.edu

In final form 20 January 1997.

C1997 American Meteorological Society appreciation for the applications of meteorological measurements for a variety of uses. Increases in agricultural activity and the need to make optimum use of scarce water resources in this region have also spurred the creation of mesoscale networks. Many of these applications are in the fields of agriculture (including forests) (Hubbard et al. 1983), air pollution, and military operations, but some are in other fields as well. In addition, as Meyer and Hubbard (1992) point out, it is now possible to monitor meteorological variables at much less cost than in the past and to use nontraditional power sources. Yet many of the surface meteorological data sources are not known to the meteorological community and many of the potential meteorological research uses for them are not realized. This paper will present a survey of current mesonets. Meyer and Hubbard (1992) presented a survey of automated weather observing networks, concentrating on nonfederal networks and looking at the entire United States. This work concentrates on the western United States, includes updated information, and includes those networks with ties to the federal government. Many networks receive some sort of federal funds to operate so that the distinction between federal and nonfederal sources does 
not appear to be relevant at this time. This summary will not include stations specifically operated by the National Weather Service (NWS). Although this paper concentrates on surface observations, several of the networks discussed make upper-air observations as well.

\section{Mesonets considered}

There are many possible definitions of a surface mesoscale meteorological network. For the purpose of this paper, a surface mesonet has the following characteristics.

1) A group of five or more stations with a spatial density of at least one station per $10000 \mathrm{~km}^{2}$.

2) Stations that record at least temperature and wind speed and direction on at least an hourly basis throughout the year. (Note that many networks measure additional variables and/or report more often.)

3) The network has existed for at least two years with plans to continue for the foreseeable future, and data are archived.

4) Some entity is committed to maintaining the instruments and the data archives for the foreseeable future.

The first two criteria emphasize that the network must be mesoscale in both space and time. A number of stations in the western United States take some weather observations once or twice a day but because of coarse time resolution their observations would not be mesoscale. The variability of wind caused by large topographic variations in this region makes it imperative that measurement of it be included in observations of general meteorological significance.

The last two requirements leave out mesonets that are set up temporarily for a specific research project. Because of their temporary nature, data from mesonets of this type are difficult to combine with other data from other sources. Since the data are focused toward the needs of a specific problem, those who are interested in a different type of problem cannot count on the data being at the right place and time for their needs. The use of such data for climatological applications is also limited to the interests of those administering the network. Likewise groups of less than five stations that are isolated from others would not be included. One additional note on criterion 4: just because data archives are kept does not mean that they will always be generally accessible.

A few exceptions to the above definition were made. The mesonet begun by the Prototype Regional Observing and Forecasting Service (PROFS) and recently maintained by the Forecast Systems Laboratory (FSL) was dismantled in September 1996. It is included, however, because it has a long history of observations. A number of individual data systems do not meet criterion 1 over their entire domains. They are included because parts of them meet criterion 1 themselves and some other parts would meet criterion 1 if combined with data from other sources.

\section{The mesonets}

A list of the mesonets and a summary of their key characteristics are given in Table 1 . In western Texas there are no networks large enough to meet the criteria listed above. Efforts are currently under way to organize mesonet activity in Texas. With this exception, all states in the region have some area with sufficient number of stations for them to be considered a mesonet.

Areas with particularly high station densities are the West Coast states and southern Arizona, especially the city of Phoenix. In the Four Corners region, as well as in parts of Nevada and Wyoming, observations are still relatively scarce. The stations are well distributed; that is, the number of instances where stations from different entities are in almost the same location are few. Most likely, organizations sought to make sure that there was no weather station recording the same variables at the same heights in the location in which they were interested before going to the expense of setting up another station.

Slightly over half of the networks recognized in this survey started in the mid-to-late 1980s. Most started with a few stations and built up to the number reporting today. For each network, the number of stations currently recording both temperature and winds is given whether or not all these stations are west of $100^{\circ} \mathrm{W}$ longitude. The network may, in some cases, have additional stations that do not measure temperature and/or winds. The year the network began is listed as the year when the first station in the network began recording data. In all 
cases the number and locations of the stations tend to vary over the course of years. At times, each entity may have operated more or fewer stations than it does at present. Locations of some stations may have changed. Most networks have at least a few stations that have been in the same locations for a number of years. Instrument packages and variables measured may also change for the same station. Most stations measure more than just the minimal number of variables. In all cases, only variables actually measured are listed; derived variables are not. Some of the networks even have data measured at more than one level. Measurements of precipitation, solar radiation, and humidity are common.

Information sources about the mesonets are listed in Table 2. If a resource is not public, then the network sponsor may charge for the data or may only release the data with special permission. One publication has been chosen for each network; thus, the publication list is not exhaustive. Some networks may have only one publication. Others may have a dozen or more.

Users of the data from any of these networks should be aware that data quality varies, even within the same network. Some networks have greater resources for quality control than others. It would be wise for users to make inquiries about the quality control mechanisms used by the network for the data they release. Likewise, many stations distribute information on derived quantities, such as evapotranspiration, which users should evaluate carefully before using. Some stations are in remote locations and it is not always possible to visit them quickly when there is an equipment failure. Most networks have current data available on the Internet or a dial-in service. Some networks will send historical data for free or post it on the Internet, others may charge considerable fees.

\section{a. U.S. government civilian laboratories}

The locations of currently reporting stations for all mesonets operated by civilian laboratories, military installations and state and local governments can be seen in Fig. 1 .

\section{1) FSL/PROFS}

The PROFS mesonet (Pratte and Clark 1983) began in 1981 and was later maintained by FSL until September 1996. Although it is no longer in existence, it is included in this survey because of its long data record. It included both plains and mountain stations in northeast Colorado. Its primary purpose was to examine the improvement in mesoscale forecasting that would be possible with increased resolution of surface observations (Schlatter et al. 1985).

\section{2) IDAHo National EngineERING LABORATORY/AIR} RESOURCES LABORATORY

The Air Resources Laboratory (ARL) has maintained meteorological stations for the Idaho National Engineering Laboratory (INEL) in eastern Idaho for about 30 years. The information in Table 1 reflects their current surface mesonet. Stations are located primarily in the valley areas and some have tall towers. Three additional stations in this network report air quality data only. The primary purpose of the network is air quality monitoring. Data from

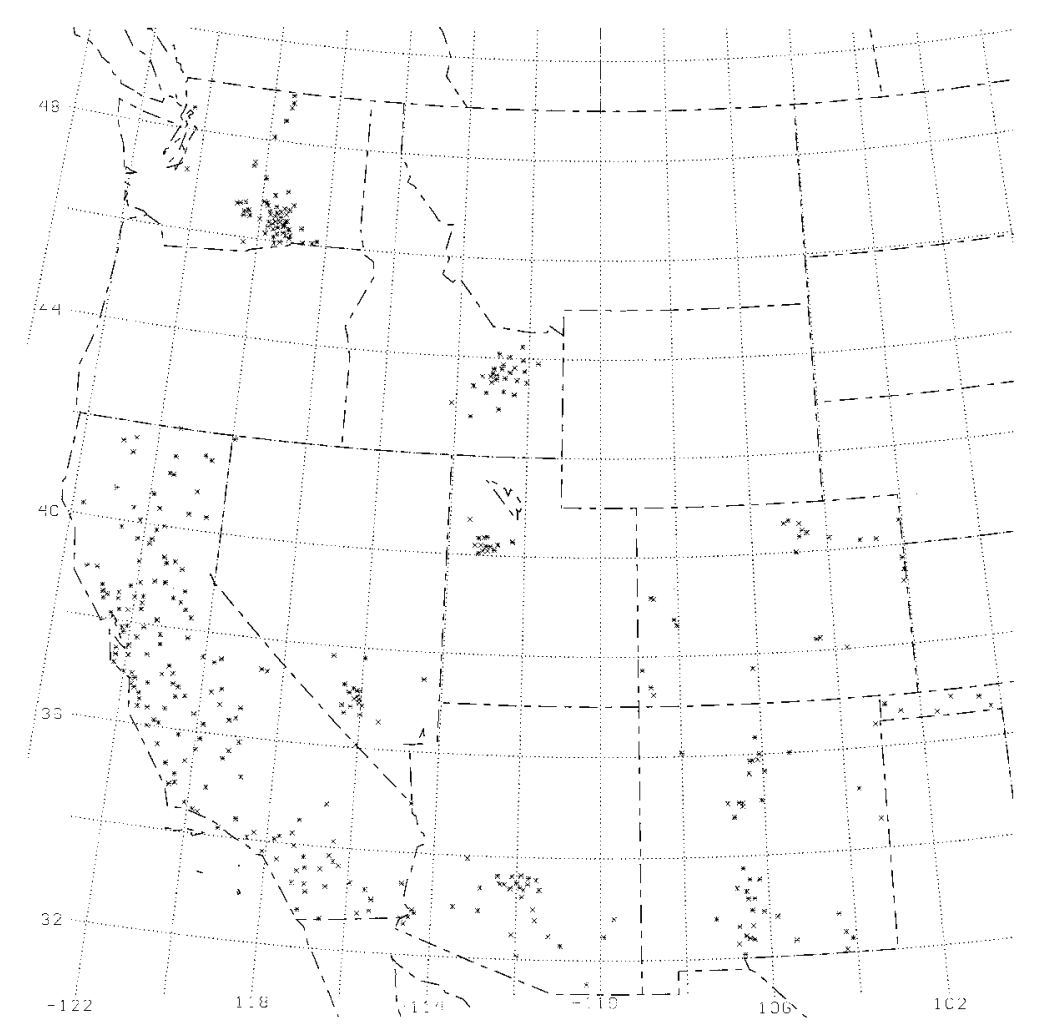

FIG. 1. Currently reporting mesonet stations sites sponsored by U.S. government civilian laboratories, military, and state governments and universities. Locations of stations are marked with asterisks. Stations that are very close to each other are plotted as one station. 
TABLE 1. Characteristics of western mesonets. Acronyms are defined in section 3 in the text. Values given in parentheses apply to some but not all of the stations in the network. For example, some but not all stations in a network may take observations at more than one height.

\begin{tabular}{|c|c|c|c|c|c|}
\hline $\begin{array}{l}\text { Network } \\
\text { sponsor }\end{array}$ & $\begin{array}{l}\text { Current number } \\
\text { of stations }\end{array}$ & $\begin{array}{l}\text { Year } \\
\text { begun }\end{array}$ & $\begin{array}{c}\text { Height of } \\
\text { temperature } \\
\text { observation } \\
\text { (m) }\end{array}$ & $\begin{array}{c}\text { Height } \\
\text { of wind } \\
\text { observation } \\
\text { (m) }\end{array}$ & $\begin{array}{c}\text { Other } \\
\text { variables } \\
\text { observed }\end{array}$ \\
\hline FSL-PROFS net & 22 & 1981 & 1.5 & 10 & $\mathrm{H},{ }^{\mathrm{b}} \mathrm{PRES}^{\mathrm{c}}{ }^{\mathrm{c}} \mathrm{SR},{ }^{\mathrm{d}} \mathrm{PREC}^{\mathrm{e}}$ \\
\hline INEL-ARL & 30 & 1968 & $\begin{array}{l}1.5,(15), \\
(76)\end{array}$ & $\begin{array}{l}15,(15) \\
(75)\end{array}$ & $\mathrm{AQ}^{\mathrm{a}}(\mathrm{H}, \mathrm{PRES}, \mathrm{SR}, \mathrm{PREC})$ \\
\hline $\begin{array}{l}\text { Nevada Test Site } \\
\text { DOE/ARL }\end{array}$ & 21 & 1960 & 10 & 10 & AQ, (H, PRES, PREC) \\
\hline $\begin{array}{l}\text { Hanford } \\
\text { DOE/Battelle }\end{array}$ & 29 & 1944 & 1 & $\begin{array}{c}10,(15, \\
122)\end{array}$ & H, SR, (PREC, PRES, VB ${ }^{\mathrm{g}}$ ) \\
\hline LANL & 6 & 1982 & 12 & $\begin{array}{c}11,23 \\
(46,92)\end{array}$ & (SR, PREC, PRES) \\
\hline LANL-Newnet & 6 & 1994 & 2 & 10 & (H, SR, PREC, PRES) \\
\hline Sandia & 7 & 1995 & 1.5 & $\begin{array}{c}10,(3 \\
50,60)\end{array}$ & (H, SR, PREC, PRES) \\
\hline Army-White Sands & 15 & 1988 & $\begin{array}{c}1.3 \\
(0.4,4)\end{array}$ & 10 & H, PRES, SR, PREC, ST, ${ }^{\mathrm{f}}$ VB \\
\hline Army-Ft. Huachuca & 19 & 1988 & 1.3 & 10 & H, PRES, SR, PREC, ST, VB \\
\hline Army-Yuma & 7 & 1988 & 1.3 & 10 & H, PRES, SR, PREC, ST, VB \\
\hline Army-Dugway & 17 & 1984 & 1.3 & 10 & H, PRES, SR, PREC, ST \\
\hline $\begin{array}{l}\text { Army-Ft. Hunter- } \\
\text { Liggett }\end{array}$ & 9 & 1988 & 1.3 & 10 & H, PRES, SR, PREC, ST \\
\hline Army-Tooele & 9 & 1988 & 1.3 & 10 & AQ, H, PRES \\
\hline Oklahoma & 111 & 1991 & $1.5,(9)$ & (2), 10 & H, PRES, SR, PREC, ST, $\left(\mathrm{LW}^{\mathrm{h}}\right)$ \\
\hline
\end{tabular}

this network are obtained and displayed in near real time by the University of Utah.

\section{3) Nevada test Site}

ARL also maintains a mesonet for the Department of Energy (DOE) at the Nevada test site in southern Nevada. This network also has a fairly long history. It includes some mountain stations.

\section{4) HANFORd DOE/BAtTElle}

DOE has taken meteorological observations in the Hanford, Washington, area since World War II.
Their current network, which includes some tall towers, is described in Table 1.

\section{5) Los Alamos National Laboratory}

The Los Alamos National Laboratory (LANL) currently has two meteorological networks. One of them has been in existence for some time; it includes some tall towers and consists of stations at the laboratory site. The other one, known as Newnet, consists of several other stations in northern New Mexico. Newnet also maintains some radiation and air quality stations in southern Nevada and Utah. 
TABLE 1. Continued.

\begin{tabular}{|c|c|c|c|c|c|}
\hline $\begin{array}{l}\text { Network } \\
\text { sponsor }\end{array}$ & $\begin{array}{l}\text { urrent number } \\
\text { of stations }\end{array}$ & $\begin{array}{c}\text { Year } \\
\text { begun }\end{array}$ & $\begin{array}{c}\text { Height of } \\
\text { temperature } \\
\text { observation } \\
\text { (m) }\end{array}$ & $\begin{array}{c}\text { Height } \\
\text { of wind } \\
\text { observation } \\
\text { (m) }\end{array}$ & $\begin{array}{c}\text { Other } \\
\text { variables } \\
\text { observed }\end{array}$ \\
\hline CIMIS & 90 & 1982 & 1.5 & 2 & H, SR, PREC, ST \\
\hline $\mathrm{CDF}$ & 65 & 1985 & 2 & 6.25 & $\mathrm{H}$ \\
\hline Washington-PAWS & 56 & 1988 & $2,(10)$ & $2,(10)$ & H, SR, PREC, ST, LW \\
\hline New Mexico & 24 & 1983 & 1.5 & 3.75 & H, SR, PREC, ST \\
\hline AZMET & 22 & 1986 & 1.5 & 3 & H, SR, ST, PREC \\
\hline PRISMS & 17 & 1991 & 1.5 & 6.25 & H, (PRES), (SR), PREC \\
\hline COAGMET & 30 & 1992 & 1.8 & 2 or 3 & H, SR, PREC, ST \\
\hline WRCC-RAWS & 662 & 1983 & varies & varies & varies \\
\hline HPCC-AWDN & 130 & 1981 & 1.5 & 3 & H, SR, PREC, (ST) \\
\hline $\begin{array}{l}\text { Bureau of Reclamation- } \\
\text { Agrimet (Pacific) }\end{array}$ & $n-$ & 1983 & 2 & 2 & H, SR, PREC, (ST) \\
\hline $\begin{array}{l}\text { Bureau of Reclamation- } \\
\text { Agrimet (Plains) }\end{array}$ & $n-$ & 1989 & 2 & 2 & H, SR, PREC, (ST) \\
\hline REINAS & 12 & 1993 & varies & varies & (H, SR, PREC, PRES) \\
\hline $\begin{array}{l}\text { Pacific Gas } \\
\text { and Electric }\end{array}$ & 13 & 1987 & 10 & $\begin{array}{l}10,(60, \\
72)\end{array}$ & \\
\hline EPA/AIRS & 151 & 1987 & $\begin{array}{c}2 \\
\text { (varies) }\end{array}$ & $\begin{array}{c}10 \\
\text { (varies) }\end{array}$ & AQ, $(\mathrm{H})$ \\
\hline
\end{tabular}

AQ: air quality; H: humidity; PRES: station pressure; SR: solar radiation; PREC: precipitation; ST: soil temperature; VB: visibility; LF: leaf wetness.

\section{6) SAndia National Laboratory}

Sandia National Laboratory has just recently started a mesoscale network. The stations are all very close together but include two tall towers.

\section{b. U.S. government-Military}

A number of military bases (mostly army) take mesoscale surface (and sometimes upper-air data) because the data are needed for military applications. There are several networks, as listed in Table 1. Again the data quality, availability, and parameters measured varies from network to network.
Generally, to obtain data the user would need to contact the individual military base. White Sands displays its data in real time on the Internet. Realtime data from Dugway and Tooele are displayed by the University of Utah. Stations in these military networks are sometimes located in the types of places where meteorological data have been quite scarce, such as mountain tops or remote valleys.

\section{c. State/local governments-State universities}

A number of states and/or state universities sponsor meteorological networks. Even if the net- 
TABLE 2. Information sources on western mesonets. Acronymns are defined in the text. Networks not listed do not have information sources.

\begin{tabular}{|c|c|c|c|}
\hline Network sponsor & Internet access & Telephone access & Publications \\
\hline FSL-PROFS net & $\begin{array}{l}\text { http://www.fsl.noaa.gov/ } \\
\text { fsl/docs/wthr/fsl-weather.html }\end{array}$ & none & $\begin{array}{l}\text { Pratte and Clark (1983) } \\
\text { Schlatter et al. (1985) }\end{array}$ \\
\hline INEL/ARL & $\begin{array}{l}\text { http://www.met.utah.edu/ } \\
\text { cgi-bin/ut_meso.cgi }\end{array}$ & none & George and Hukari (1996) \\
\hline $\begin{array}{l}\text { Nevada Test Site } \\
\text { DOE/ARL }\end{array}$ & none & not public & Randerson (1987) \\
\hline LANL & http://weather.lanl.gov & none & Bowen (1996) \\
\hline LANL-Newnet & $\begin{array}{l}\text { http://newnet.jdola.lanl.gov/ } \\
\text { newnet.html }\end{array}$ & none & none \\
\hline Army-White Sands & http://155.148.19.139/climo.htm & not public & Tucker and Bonner (1990) \\
\hline Army-Dugway & $\begin{array}{l}\text { http://www.met.utah.edu/ } \\
\text { cgi-bin/ut_meso.cgi }\end{array}$ & none & Tucker and Bonner (1990) \\
\hline Army-Tooele & $\begin{array}{l}\text { http://www.met.utah.edu/ } \\
\text { cgi-bin/ut_meso.cgi }\end{array}$ & none & none \\
\hline Oklahoma & $\begin{array}{l}\text { http://geowww.gcn.uoknor.edu/ } \\
\text { WWW/Mesonet/Mesonet.html }\end{array}$ & subscription only & Brock et al. (1995) \\
\hline CIMIS & http://www.water.ca.gov & $1-800-955-6837$ & Snyder and Pruitt (1992) \\
\hline $\mathrm{CDF}$ & http://cyclone.water.ca.gov & not public & none \\
\hline
\end{tabular}

work is state sponsored (i.e., not solely for the university) the logistical details, such as setup and maintenance, of the network are often handled by a state university. Thus, the roles of the two entities as network sponsors are difficult to separate. Many networks have a primary purpose of collecting data for agricultural applications (including forestry), but they may serve a variety of purposes.

\section{1) OKLAHOMA}

This network is probably the largest of those run by a state. The western portion (which includes six stations) of it would be in the domain considered by this paper. The number of stations listed in Table 1 is for the entire state of Oklahoma. Stations throughout this network make the same set of measurements (Brock et al. 1995). A special effort was made during the network setup to ensure that the stations were distributed as evenly as possible throughout the state.

\section{2) CALIFornia}

Data from a network set up by the California Department of Water Resources in cooperation with the University of California, Davis, can be accessed from the California Irrigation Management Information System (CIMIS). This network has included a large number of stations in its past, a significant number of which are still operating.

The California Department of Forestry (CDF) operates almost as many stations as CIMIS to help in the management of forests and forest fires. CDF cooperates closely with the National Forest Service's part of the RAWS network (see section d). The CDF stations are sometimes also referred to as RAWS stations but their set of stations does not overlap with those in the RAWS network overseen by the West- 
TABle 2. Continued.

\begin{tabular}{|c|c|c|c|}
\hline Network sponsor & Internet access & Telephone access & Publications \\
\hline Washington-PAWS & $\begin{array}{l}\text { http://www.tricity.wsu.edu/htmls/ } \\
\text { iarec/iarecht.html }\end{array}$ & $\begin{array}{l}509-786-4110 \\
509-786-4009 \\
509-786-2897\end{array}$ & Ley et al. (1996) \\
\hline New Mexico & http://weather.nmsu.edu & $505-646-5362$ & Mott et al. (1992) \\
\hline AZMET & http://ag.arizona.edu & $520-621-1197$ & Brown and Yitayew (1988) \\
\hline PRISMS & none & none & Brazel et al. (1993) \\
\hline COAGMET & http://ulysses.atmos.colostate.edu & none & Duke (1996) \\
\hline WRCC-RAWS & http://wrcc.sage.dri.edu & subscription only & none \\
\hline HPCC-AWDN & http://hpccsun.unl.edu & $402-472-5575$ & Hubbard et al. (1983) \\
\hline $\begin{array}{l}\text { Bureau of Reclamation- } \\
\text { Agrimet (Pacific) }\end{array}$ & http://www.pn.usbr.gov/agrimet & $208-378-5305$ & Gardiner (1994) \\
\hline $\begin{array}{l}\text { Bureau of Reclamation-- } \\
\text { Agrimet (Plains) }\end{array}$ & $\begin{array}{l}\text { http://www.gp.usbr.gov/www/ } \\
\text { agrimet.htm* }\end{array}$ & $208-378-5305$ & Gardiner (1994) \\
\hline REINAS & http://csl.cse.ucsc.edu/reinas & none & Nuss et al. (1996) \\
\hline Pacific Gas and Electric & none & not public & Thuillier (1987) \\
\hline EPA/AIRS & http://www.epa.gov/airs/aqs.html ${ }^{*}$ & not public & none \\
\hline
\end{tabular}

*Information only, no actual data available.

ern Regional Climate Center. CDF also receives data from isolated stations run by cities and counties in California. Although California is a large state, the existence of multiple large networks means that it is rather densely instrumented.

\section{3) ArizonA}

There are two networks in this category in the state of Arizona. AZMET was set up primarily for agricultural applications and is a cooperative effort between the University of Arizona, the city of Phoenix, and the Arizona Metropolitan Water Users Association. Stations are in southern Arizona, and some of the stations are isolated from others. In several places data from these stations would have to be combined with that of other networks to produce a mesonet as defined in section 2 .

In connection with the Salt River Project and Arizona State University, the city of Phoenix spon- sors the Phoenix Real-Time Instrumentation for Surface Meteorological Studies (PRISMS). As might be expected, stations are concentrated in the greater Phoenix metropolitan area. Thus, it appears that the Phoenix area is rather densely instrumented.

\section{4) New Mexico}

The New Mexico network primarily serves agricultural interests. In places, it would meet the definition of mesonet as defined above. Some stations, however, are isolated from others.

\section{5) COAGMET}

As implied by the title, the Colorado network also emphasizes agricultural applications. This network is maintained by Colorado State University. Most of its stations are in northeast Colorado, but there are a few in the western part of the state. 
6) Washington Public Agriculture Weather SySTEM

The Washington Public Agriculture Weather System (PAWS) is run by the Washington State University and again concentrates on agricultural needs. This network functions closely with the Agrimet network (discussed below) and the NWS. Stations are concentrated in central Washington State and are most dense in the southern part of the region.

\section{d. Climate centers}

The Western Regional Climate Center (WRCC) and the High Plains Climate Center (HPCC) serve as repositories for data taken by other agencies, among them the National Forest Service, the Bureau of Land Management, and the Department of the Interior. The WRCC archives and distributes these data as the Remote Automated Weather System (RAWS) and the HPCC as the Automated Weather Data Network (AWDN). Since the agencies that take the measurements each want the data for their own purposes, the stations do not really make up a coherent network. There are a large number of these stations, as seen in Fig. 2, with at

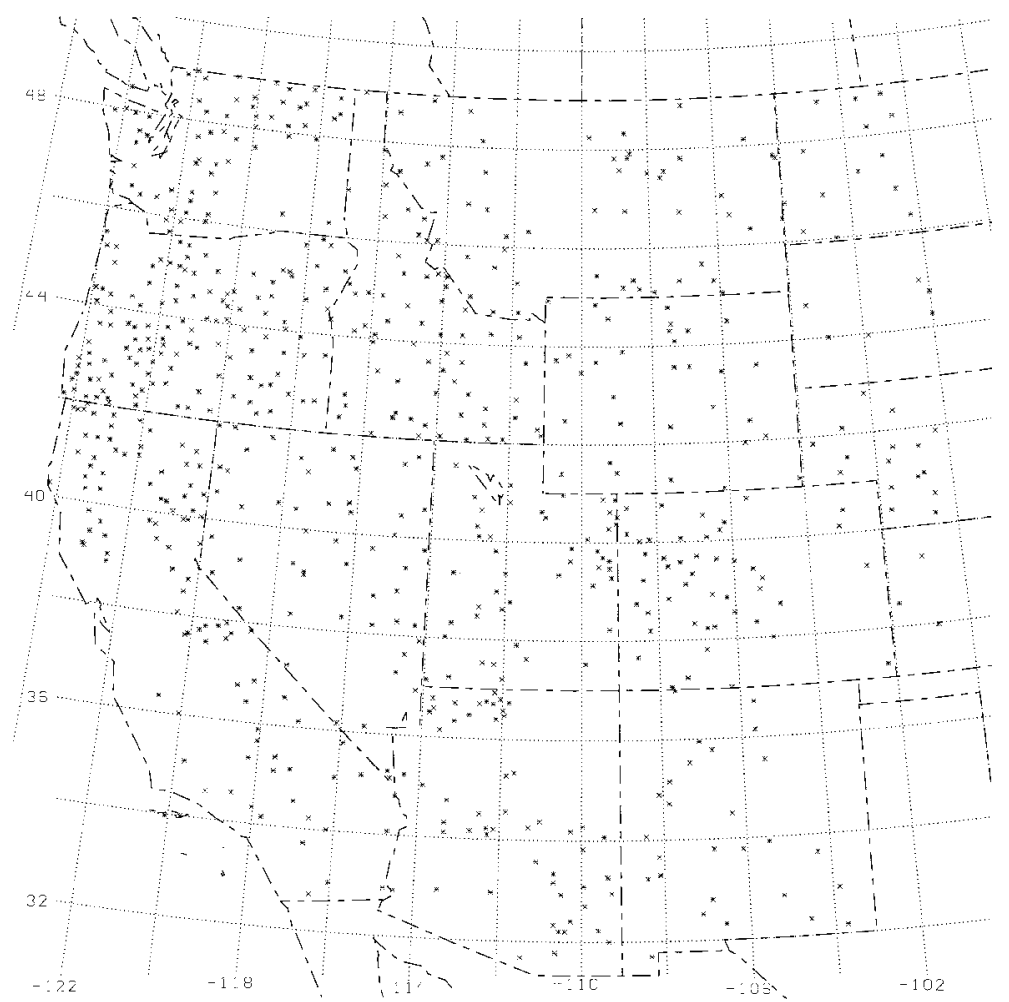

FIG. 2. Currently reporting RAWS and AWDN stations. Locations of stations are marked with asterisks. least 25 stations per state (for states that are entirely west of $\left.100^{\circ} \mathrm{W}\right)$. The stations are not evenly distributed by state; Oregon has almost 150. In many places they may meet the density resolution for mesonets as described in section 2. In other cases, their data would have to be merged with those of other networks to produce a mesonet meeting of the criteria described above. All stations take temperature and wind measurements but other variables vary widely from station to station.

\section{e. Specialized applications}

The locations of all currently reporting stations in this category can be seen in Fig. 3.

\section{1) BuREau of ReClamation}

The U.S. Bureau of Reclamation cooperates with the U.S. Department of Agriculture and various utility companies to produce the Agrimet network. Two regional offices are active in this venture. The Great Plains office maintains stations in Montana, and the Pacific Northwest office oversees stations that are predominantly located in Idaho, Oregon, and Washington. The stations are intended for water conservation and evapotranspiration measurements. In the near future, WRCC expects to be able to distribute the Agrimet data.

\section{2) REINAS}

The Real-Time Environmental Information Network and Analysis System (REINAS) is a cooperative venture between the Naval Postgraduate School; the University of California, Santa Cruz; and the Monterey Bay Aquarium Research Institute. The REINAS project aims to develop techniques for displaying high-frequency and high-volume datasets. This network is unique in that it includes some buoy stations off the California coast. It also includes a couple of mountain stations. The land-based stations are sometimes at the top of buildings so that the height of the stations above the earth's surface is not uniform.

3) Pacific Gas and Electric

Most meteorological measurements taken by private companies are 
short term and related to a specific project. Thus their mesonets are not typically in place for over two years. Pacific Gas and Electric, however, has operated a mesonet in the Diablo Canyon area for almost 10 years. Although the stations do not take measurements of many parameters, two tall tower stations are included in the network.

\section{4) EPA}

The Environmental Protection Agency (EPA), in cooperation with local governments, maintains a database of observations known as the Aerometric Information Retrieval System (AIRS) from stations taking air quality measurements. Many of these stations also take wind and temperature measurements. The stations tend to be located near major metropolitan areas. The data from these stations are not routinely made public and may be difficult to obtain.

\section{Summary and conclusions}

In recent years, the western part of the United States has gone from having relatively sparse surface data to having dense surface observations. Especially when combined with the data from the new ASOS and AWOS stations, the number of surface observations in this part of the country has become considerable. Trends are likely to continue for additional meteorological observations to be made as the importance of these operations for new applications becomes apparent. For example, a private company that packages weather-observing equipment for golf courses is planning future expansion into this region. Plans are under way to organize and expand the limited number of observations in Texas (Gammon et al. 1995).

Since the vast majority of these networks were set up for specific applications, many of which are nonmeteorological, the meteorological implications of many of these datasets are largely unexplored. The sites of stations chosen for a particular application may not be appropriate for general meteorological use. Variations in calibration schedules for different sta- tions can also cause the data from them to be difficult to interpret. Thus, these networks would not generally be useful for a study that was heavily dependent on the records of one particular station. Data from an entire network taken together can show an overall pattern. Data from White Sands Missile Range network have been used to confirm the presence and nature of the mountain-valley flow in that region (Tucker 1993). Many general principles of mountain meteorology are known and their implications for some areas have been well studied, but their applications to many specific regions have not been thoroughly investigated. These new denser observations could provide a fresh source of data for these studies.

Unfortunately, these networks all have diverse standards for their measurements. This situation is reflected in the different heights at which temperature and wind are measured, as shown in Table 1. The status of standardized heights of instrumentation is no better than that at the time of the Meyer and Hubbard (1992) paper. The problem arises partially because of the diversity of applications for which the data were originally sought. The spon-

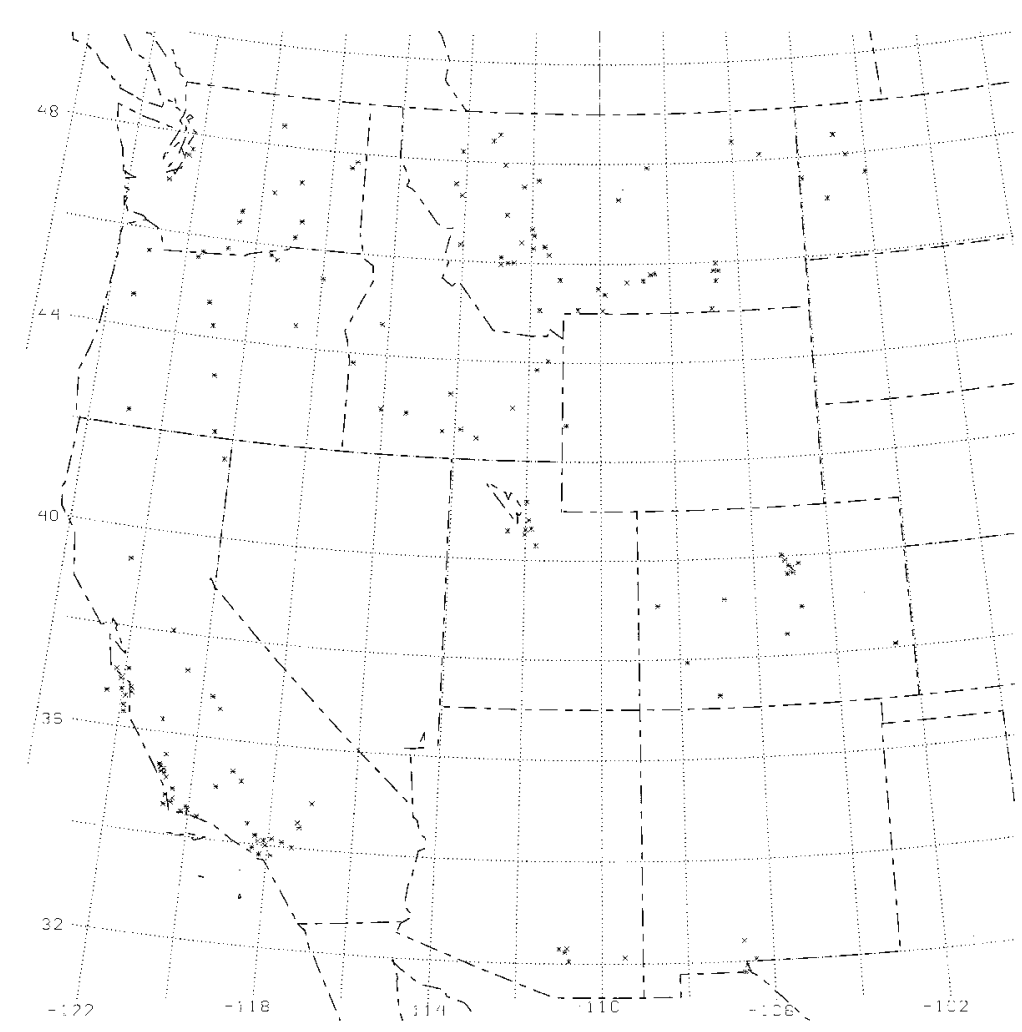

FIG. 3. Currently reporting stations from mesonets devoted to specialized applications. Locations of stations are marked with asterisks. Stations that are very close to each other are plotted as one station. 
sors of some networks have strong reasons for wanting a particular specification for their networks. Unfortunately, there are networks that serve the same application whose wind measurement heights are quite dissimilar. It is unlikely that uniformity in a variable such as the height of the wind measurement could be achieved unless all stations were to take wind measurements at more than one height. This solution will be an expensive one and unlikely to occur unless one network wanted data at stations of another one enough to merge their standards. In some cases, more than one network is funded by an individual state. This situation is also potentially expensive. The administrators of all networks need to ask themselves what compromises they would be willing to make in types and heights of measurements made in order to obtain a greater quantity or quality of data.

The difficulties of combining data from different sources with different standards poses a problem for meteorological research. Even more troubling is the variation in quality control procedures (or sometimes the lack thereof) between networks. To use these data, researchers would need to ascertain what quality control had been done. In some cases researchers would need to do their own quality control on the data. One way to alleviate these problems would be to have some recognized standards for calibration and quality control of mesonet data. Nonetheless, such obstacles to the use of these data for meteorological research should not be insurmountable.

There is no one location to obtain data from the mesonets. Although WRCC and HPCC have collected data from a number of sources, many others are not included in their archives. Some states, such as California and Utah, have attempted to create a central location to distribute mesonet data collected within their states. In many cases, however, the sponsor of each individual network must be contacted to obtain its data. Data from networks whose instruments are well maintained could also be useful for weather forecasting if the observations were more widely reported. Most networks have some facility for reporting data in real time. An attempt has been made in Utah to collect data from several mesonets in real time for use in weather forecasting and perhaps research.

It is hoped that greater awareness of these mesoscale networks will promote the greater use of their data by the meteorological community.
Certainly the difficulties of combining data from different networks are daunting, but the value of these data for research and forecasting can only be assessed if there are attempts made to use them. Perhaps in the future the people who plan and maintain these networks would maximize their cooperation so that there would be greater standardization in their measurements. All these people should be encouraged to realize the meteorological value of the data they obtain and make them available to the meteorological community at minimum cost.

Acknowledgments. This project was funded by NSF Grant ATM-9622820. The author is grateful to the administrators of all the mesonets represented in this paper for answering questions about their systems. The manuscript benefited from the comments of Fred Brocke and two anonymous reviewers. Thanks also go to Bruce Gammon and Ronald Baskett for calling my attention to several of the mesonets listed here.

\section{References}

Bowen, B. M., 1996: Rainfall and climate variation over a sloping New Mexico plateau during the North American Monsoon. J. Climate, 9, 3432-3442.

Brazel, A. J., H. J. Verville, and R. Lougeay, 1993: Spatial-temporal controls on cooling degree hours: An energy demand parameter. Theor. Appl. Climatol., 47, 81-92.

Brock, F. V., K. C. Crawford, R. L. Elliott, G. W. Cuperus, S. J. Stadler, H. L. Johnson, and M. D. Eilts, 1995: The Oklahoma mesonet: A technical overview. J. Atmos. Oceanic Technol., 12, 5-19.

Brown, P. W., and M. Yitayew, 1988: Near-real time weather information for irrigation management in Arizona. Proc. Conf. Irrigation and Drainage Division of ASCE, Lincoln, NE, ASCE, 708-715.

Cionco, R. M., 1994: Overview of the Project WIND Data. Mesoscale Modeling of the Atmosphere, Meteor. Monogr., No. 47, Amer. Meteor. Soc., 63-71.

Duke, H. R., 1996: COAGMET-Colorado Agricultural Meteorological Network. Proc. Sixth Int. Conf. on Evaporation and Irrigation Scheduling, San Antonio, TX, American Society of Agricultural Engineers, 704-709.

Gammon, B. E., E. J. Zipser, J. W. Nielsen-Gammon, N. W. Tindale, J. G. Guynes, R. E. Orville, and M. I. Biggerstaff, 1995: Texas MesoNet: A plan for a Texas mesoscale meteorological monitoring network. Cooperative Institute for Applied Meteorological Studies Rep., 128 pp. [Available from Texas A\&M University, Dept. of Meteorology, College Station, TX 77843-3150.]

Gardiner, D., 1994: Space-age network delivers weather data to the northwest. Irrigation J., 44, 22-25.

George, D. H., and N. F. Hukari, 1996: Real-time meteorological network data quality assurance/quality control. Proc. ANS 1996 Annual Meeting, Reno, NV, 55-59.

Hubbard, K. G., N. J. Rosenberg, and D. C. Nielsen, 1983: Automated weather data network for agriculture. J. Water Resour. Planning Manage., 109, 213-222. 
Knight, C. A., Ed., 1982: The Cooperative Convective Precipitation Experiment (CCOPE), 18 May-7 August 1981. Bull. Amer. Meteor. Soc., 63, 386-398.

Ley, T. W., R. G. Allen, and R. W. Hill, 1996: Weather station siting effects on reference evapotranspiration. Proc. Sixth Int. Conf. on Evaporation and Irrigation Scheduling, San Antonio, TX, American Society of Agricultural Engineers, $727-$ 734.

Meyer, S. J., and K. G. Hubbard, 1992: Nonfederal automated weather stations and networks in the United States and Canada: A preliminary survey. Bull. Amer. Meteor. Soc., 73, 449-457.

Mott, P., T. W. Sammis, and R. Jackson, 1992: Automatic weather data collection and processing. Comput. Electronics Agric., 7, 337-345.

Nuss, W. A., P. E. Mantey, A. Pang, and D. D. E. Long, 1996: The Real-Time Environmental Information Network and Analysis System (REINAS). Preprints, 12th Int. Conf. on Interactive Information and Processing Systems for Meteorology, Oceanography, and Hydrology, Atlanta, GA, Amer. Meteor. Soc., 337-339.

Orgill, M. M., and R. I. Schreck, 1985: An overview of the ASCOT multi-laboratory field experiments in relation to drainage winds and ambient flow. Bull. Amer. Meteor. Soc., 66, 1263-1277.
Pratte, J. F., and R. J. Clark, 1983: PROFS MESONET-Description and performance. Preprints, Fifth Symp. on Meteorological Observations and Instrumentation, Toronto, ON, Canada, Amer. Meteor. Soc., 303-307.

Randerson, D., 1987: Meteorological support activities at Nevada Test Site. Proc. Information Meeting on Meteorological Requirements for Emergency Response and Assessment Activities at DOE Sites, Oak Ridge, TN, U.S. Department of Energy, 1-8.

Schlatter, T. W., P. Schultz, and J. M. Brown, 1985: Forecasting convection with the PROFS system: Comments on the summer 1983 experiment. Bull. Amer. Meteor. Soc., 66, 802-809.

Snyder, R. L., and W. O. Pruitt, 1992: Evapotranspiration data management in California. Proc. Water Forum '92 Conference on Irrigation and Drainage, Baltimore, MD, American Society of Civil Engineers, 128-133.

Thuillier, R. H., 1987: Real-time analysis of local wind patterns for application to nuclear-emergency response. Bull. Amer. Meteor. Soc., 68, 1111-1115.

Tucker, D. F., 1993: Diurnal precipitation variations in South Central New Mexico. Mon. Wea. Rev., 121, 1979-1991.

— taken by the U.S. Army Atmospheric Sciences Laboratory. U.S. Army Laboratory Command, Atmospheric Science Laboratory, 24 pp. [Available from U.S. Army Research Laboratory, White Sands Missile Range, NM 88002-5501.] 